\title{
A Missense Mutation (R723H) in the Head mOtor Domain of $\beta$-MYH7 gene in an Indian HCM Patient and Phenotypic Plasticity
}

Deepa Selvi Rani $^{1 *}$, Gnana Veera Subhashini ${ }^{2}$, Ambure Sharadhadevi ${ }^{1}$, Emmanuel Cyril ${ }^{3}$, Kumarasamy Thangaraj ${ }^{1,4 *}$

${ }^{1}$ CSIR-Centre for Cellular and Molecular Biology, Hyderabad, India.

${ }^{2}$ Baba Clinical and Genomic Research Centre, CSIR Road, Taramani, Chennai, India.

${ }^{3}$ Academics and Research, Global Hospitals and Health City, Chennai, India

${ }^{4}$ Centre for DNA Fingerprinting and Diagnostics, Hyderabad, 500039, India.

*Corresponding Author: Deepa Selvi Rani, CSIR-Centre for Cellular and Molecular Biology Uppal Road, Hyderabad 500 007 , India.

Received Date: September 09, 2021; Accepted Date: October 18, 2021; Published Date: October 25, 2021

Citation: Deepa Selvi Rani, Gnana Veera Subhashini, Ambure Sharadhadevi, Emmanuel Cyril, Kumarasamy Thangaraj. (2021) A Missense Mutation $(\mathrm{R} 723 \mathrm{H})$ in the Head mOtor Domain of $\beta-\mathrm{MYH} 7$ gene in an Indian HCM Patient and Phenotypic Plasticity. J. Clinical Cardiology and Cardiovascular Interventions, 4(17); Doi:10.31579/2641-0419/219

Copyright: (C) 2021 Deepa Selvi Rani, This is an open-access article distributed under the terms of the Creative Commons Attribution License, which permits unrestricted use, distribution, and reproduction in any medium, provided the original author and source are credited.

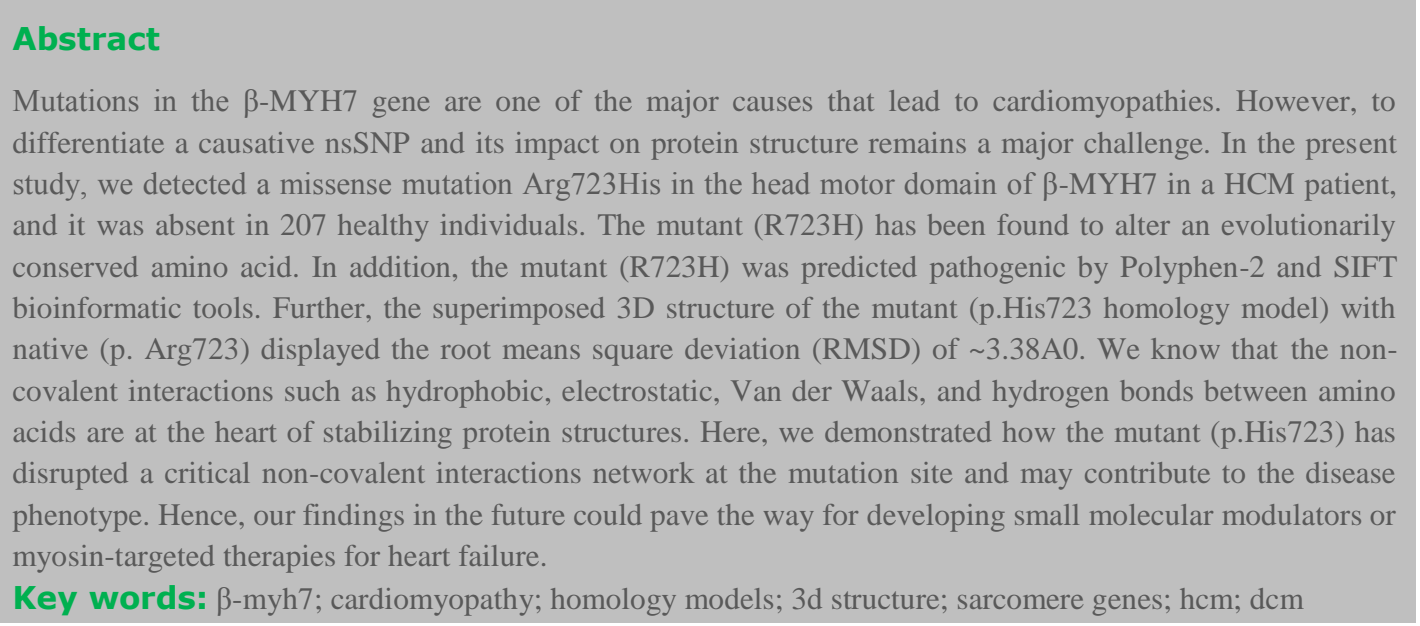

\section{Introduction}

In general, non-synonymous Single Nucleotide Polymorphisms (nsSNPs) lead to change an amino acid of the encoded protein. They may affect protein structure, stability, and function, which may cause various diseases in humans [1-4]. About $\geq 50 \%$ of amino acids change are linked with genetic disorders $[5,6]$. However, a few amino acids change have remained uncharacterized in genes [7]. Mutations in the sarcomere proteins were reported to cause cardiomyopathies in various populations [8-15]. However, identifying the causative nsSNPs and their association led to disease is challenging. Cardiomyopathy is classified into Hypertrophic (HCM) and dilated (DCM) based on their heart muscle structure[16]. The HCM is characterized by excessive left ventricular thickening, arrhythmia, diastolic dysfunction, left ventricular outflow obstruction, myocardial ischemia, mitral regurgitation, and sudden death, with an estimated prevalence of 1:500[17]. Mutations in sarcomere genes predominantly cause HCM, of which $\sim 75 \%$ of mutations were reported in the $\beta-M Y H 7$ and $M Y B P C 3$ genes [6,18-26]. Though the recent nextgeneration sequencing (NGS) technology has significantly increased our knowledge about disease alleles [27,28], we are far from completely understanding the impact of deleterious alleles on disease phenotype. We know that a few mutations may lead to a misfolding and nonfunctional form of proteins to accumulate and which may cause diseases. More importantly, the interactions between constituent amino acids in a protein determine its 3D structure and function [29]. Here, we have demonstrated a deleterious effect of a missense mutation (Arg723His) on $\beta$-MYH7 protein structure using (p.His723) homology modeling, an Insilco analysis.

\section{Materials and Methods}

\section{Ethical statement and clinical evaluation}

We enrolled a total of 50 hypertrophic cardiomyopathy patients (HCM) from 2 hospitals (Table 1). They were (a) Baba Clinical and Genomic 
Research Centre, CSIR Road, Taramani, Chennai, India, and (b) Academics and Research, Global Hospitals and Health City, Chennai, India. Along with 207 healthy volunteers matched for the age, sex and ethnicity were recruited as controls (Table 1), provided they had normal ECG and echocardiograph measurements and were unrelated to the HCM patients. The Institutional Ethical Committees (IEC) of all three institutes have approved the study. Before the sample collection, informed written consent was obtained from all patients and controls to fulfill the requirements of relevant guidelines and regulations that permitted research on human subjects, which has followed the ethics of the Declaration of Helsinki, the World Medical Association.

\begin{tabular}{|l|c|c|}
\hline Baseline characteristics & HCM (N=50) & Controls $(\mathbf{N = 2 0 7 )}$ \\
\hline Age (Yrs) & $49 \pm 12$ & $50.0 \pm 0.2$ \\
\hline Sex, males (\%) & 61 & 63 \\
\hline Dyspnea or shortness of breath \% & 67 & 0 \\
\hline Angina pectoris (chest pain) \% & 56.8 & 0 \\
\hline Syncope (fainting) \% & 31.9 & 0 \\
\hline Abnormal ECG \% & 57.4 & 0 \\
\hline LVEDD, mm & $36 \pm 6.5$ & $51.3 \pm 2.7$ \\
\hline LVESD, mm & $20.8 \pm 3.7$ & $32.1 \pm 1.2$ \\
\hline Septum, mm & $22.1 \pm 4.2$ & $9.0 \pm 0.2$ \\
\hline Family History \% & 37 & 0 \\
\hline Sudden cardiac death \% & 21.8 & 0 \\
\hline
\end{tabular}

NYHA-New York Heart Association; LVEDD-left ventricular end-diastolic dimension;

LVESD-left ventricular end-systolic dimension; ECG-Electrocardiogram;

LVEF-Left ventricular ejection fraction; SCD-Sudden cardiac death.

Table 1: Clinical baseline characteristics of HCM patients with control

\section{Genetic studies}

The patients and controls DNA was extracted from peripheral blood samples, amplified using polymerase chain reaction (PCR), as described elsewhere [13]. The amplicons were purified using Exonuclease 1 and Shrimp alkaline phosphatase, following the manufacturer's instructions (USB Corporation, 26, 111 Miles Road, Cleveland, Ohio 44128, USA). The purified amplicons were sequenced bi-directionally using the ABI Big Dye terminator cycle sequencing kit (Perkin-Elmer, Foster City, CA, USA) and ABI 3730 DNA Analyzer (Applied Biosystems, Foster City, CA, USA). Using Auto-Assembler software from Applied Biosystems (Foster City, CA, USA), the sequences were edited and screened for variations compared with the respective reference sequence obtained from Gen-Bank.

\section{In silico analyses}

A nonsynonymous single-nucleotide variant observed in our study was analysed using two bioinformatics tools, PolyPhen-2 (Polymorphism Phenotyping v2; http://genetics.bwh.harvard.edu/pph2/) [30] and SIFT (Sorting Intolerant From Tolerant; http://siftdna.org/www/Extended_SIFT_chr_coords_submit.html). [31] Further, we built a homology model for a mutant of $\beta$-MYH7 by SWISSMODEL Repository System (SMTL) (http://swissmodel.expasy.org)
[32], using 3D native template structure having $99 \%$ similarity obtained from the RCSB protein data bank (PDB) (http://www.rcsb.org/pdb/explore/explore.do?structureId=4P7H) [33]. To understand the impact of a nsSNP on $\beta-\mathrm{MYH} 7$ protein structure, we first superimposed the homology model of $\beta-\mathrm{MYH} 7$ with native $\beta-\mathrm{MYH} 7$ protein template structure to measure their root-mean-square deviations (RMSD) between the atoms (backbone atoms) of the superimposed pairs. We second studied the non-bonding interactions (created/destroyed) at the mutation site of the homology model vs. native $\beta$-MYH7. We then plotted the hydrophobicity plot and Ramachandran plot and studied the homology model vs. native $\beta-M Y H 7$.

\section{Results}

In the present study, we detected a missense mutation $(\mathrm{R} 723 \mathrm{H})$ in the head motor domain of $\beta$-MYH7 (Fig.1A). We found that the mutant (R723H) has altered the evolutionarily conserved amino acid across many species (Figure 1A, B). The mutant (p. His723) was predicted pathogenic by Polyphen2 and SIFT bioinformatics tools. Further, to understand the impact of mutant (Arg723His) on its protein structure, we first superimposed the mutant (p.His723_homology model) with native $\beta$ MYH7 protein (p.Arg723) and measured their root-mean-square deviation (RMSD), it was $\sim 3.86 \mathrm{~A}^{\circ}$. 
A

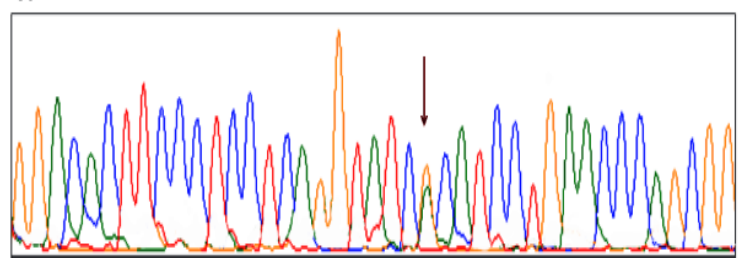

GGACACTTCCCTCCTCAGGTALTCOCATCCTGAACCCAGCGG

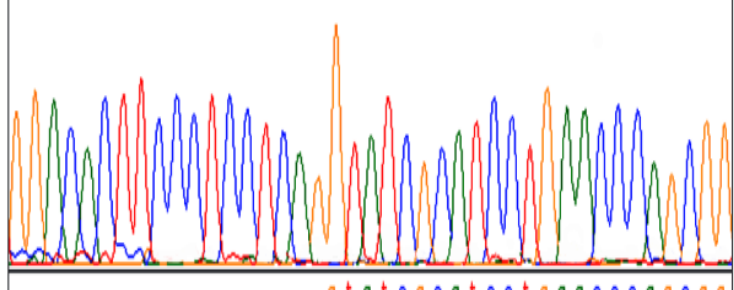

B

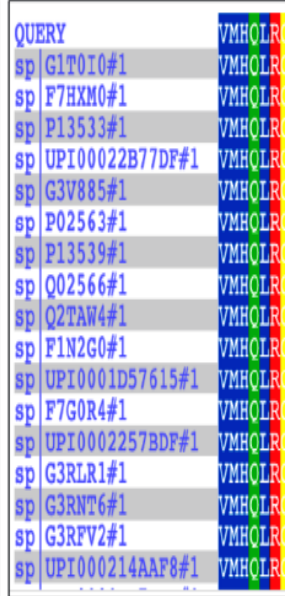

$\downarrow$

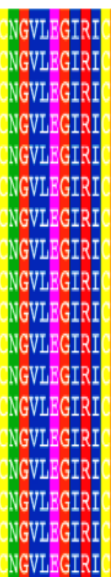

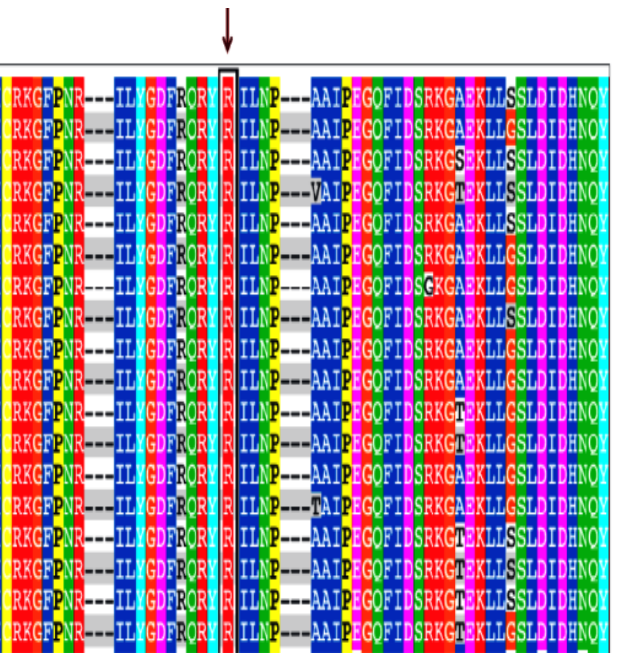

Figure 1A: Electropherograms (arrows) showing a missense mutation CGC $\rightarrow C A C$ (p.Arg723His), in the $\beta$-MYH7 gene.

Figure 1A: Multiple alignments of amino acid sequences in the $\beta$-MYH7 gene of several species, showing that the amino acid p.Arg723 is highly conserved across many species

We then compared the non-bonding interactions of a homology model (p.His723) vs. native $\beta$-MYH7 protein to understand the mutational impact on protein structure and function (Table 2; Figure 2). Here, we observed that the mutant His723 forms a peculiar hydrophobic interaction with Pro727 (A), which, in turn, forms a hydrogen bond with another nearby proline residue Pro731 (B). As a result, a hydrophobic interaction between two isoleucine residues (Ile730 and Ile736) has been destroyed (C) due to an increased van der Waals radius (Table 2; Figure 2). Further, the mutant p.His723 also destroys two electrostatic salt bridges; Arg723 with Glu981 (D) and Glu981 with Lys865 (E) (Table 2; Figure 2). We know that the proline residue is unique and lacks an amide proton; therefore, it can't donate hydrogen to stabilize other bonds or promote stability, thus possibly making the mutant structure very rigid. The deviations in the mutant could be clearly understood when we compare the hydrophobic interaction distances between the native $\operatorname{Arg} 723$ with Ala729 $\left(4.69 \mathrm{~A}^{0}\right)$ in the template (F1) and the mutant His723 with Ala729 $\left(3.93 \mathrm{~A}^{0}\right)$ in the homology model (F2) (Table 2; Figure 2).

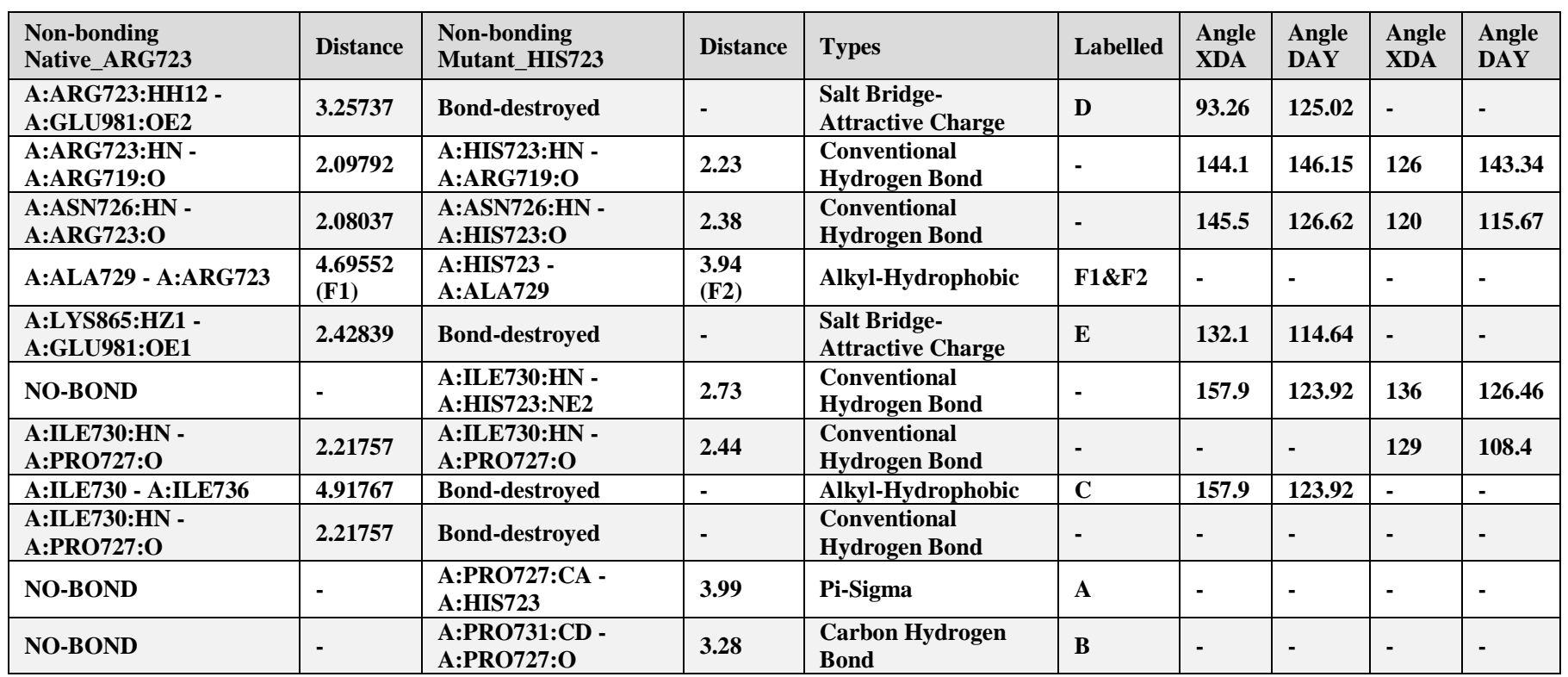

Table 2: The non-bonding interactions of a homology model p.His 723 Vs. native template p.Arg723 of $\beta$-MYH7 at the mutation site 

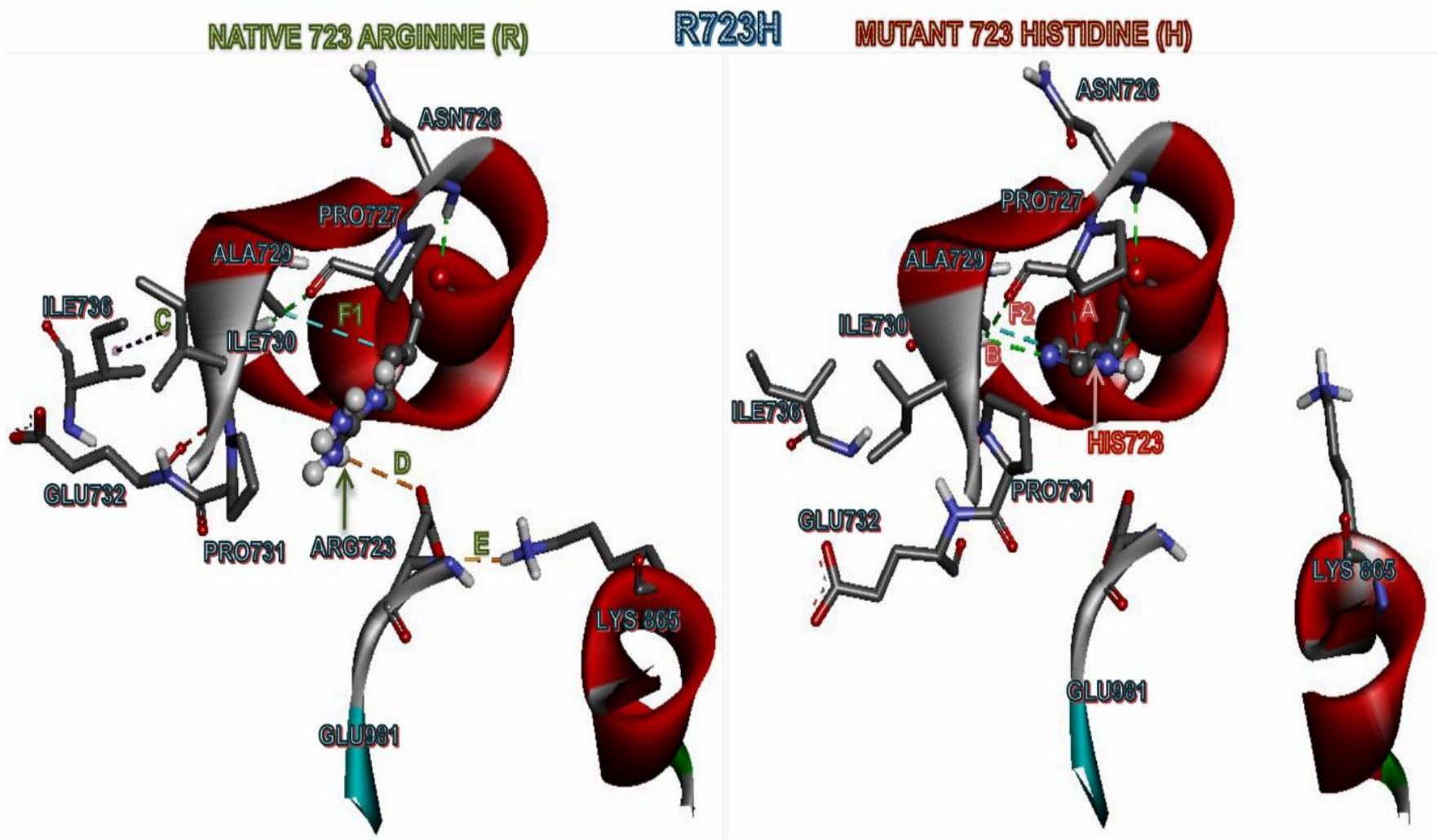

Figure 2: Non-bonding (NB) interactions at the site of amino acid substitution in a $\beta$-myosin mutant homology models vs. native template.

We plotted the hydrophobicity plot to compare the hydrophobicity index of native protein Vs. mutant protein (Figure 3; Table S1).

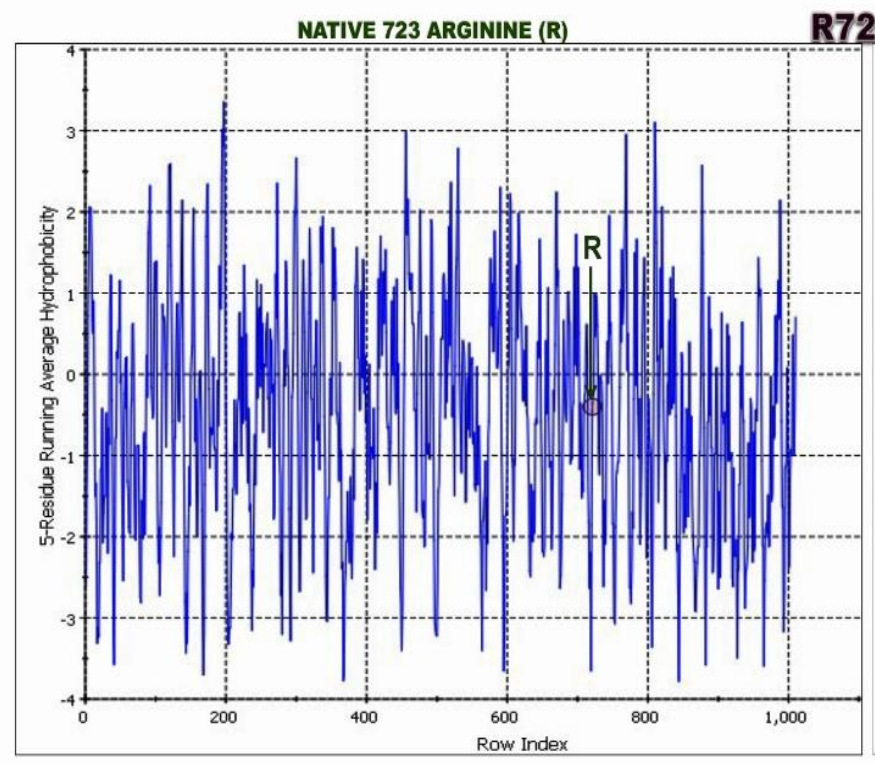

R723H

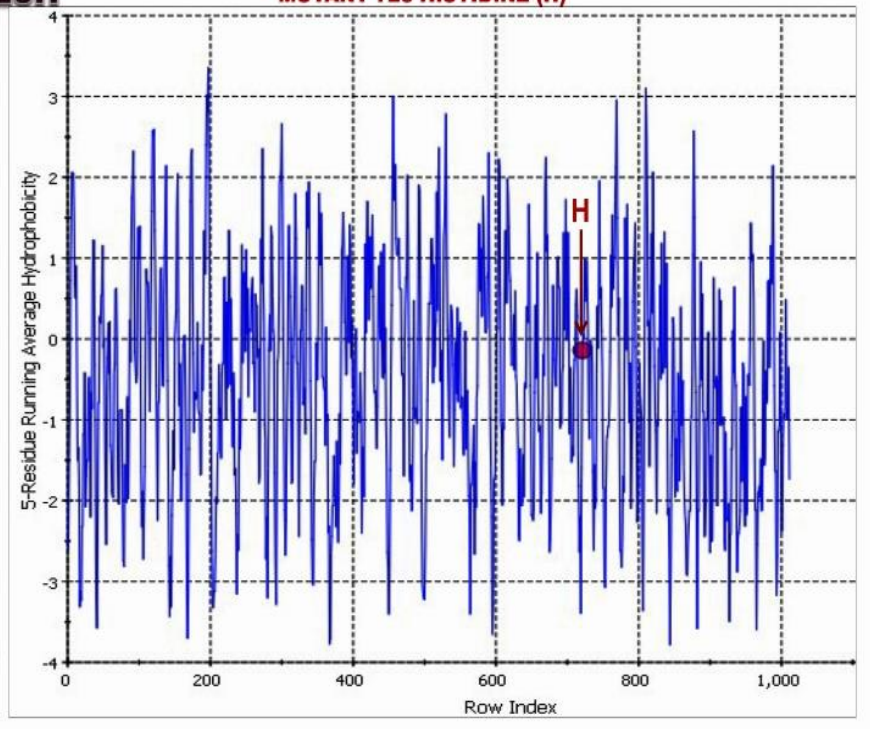

Figure 3: Hydrophobicity plot, we compared the amino acids in the native protein Vs mutant protein against their hydrophobicity index

We then studied the Ramachandran plot to compare the energetically allowed and disallowed regions of backbone dihedral angles $\psi$ against $\phi$ of amino acid residues in the mutant (homology model) vs. native (Figure.4; Table S2). 


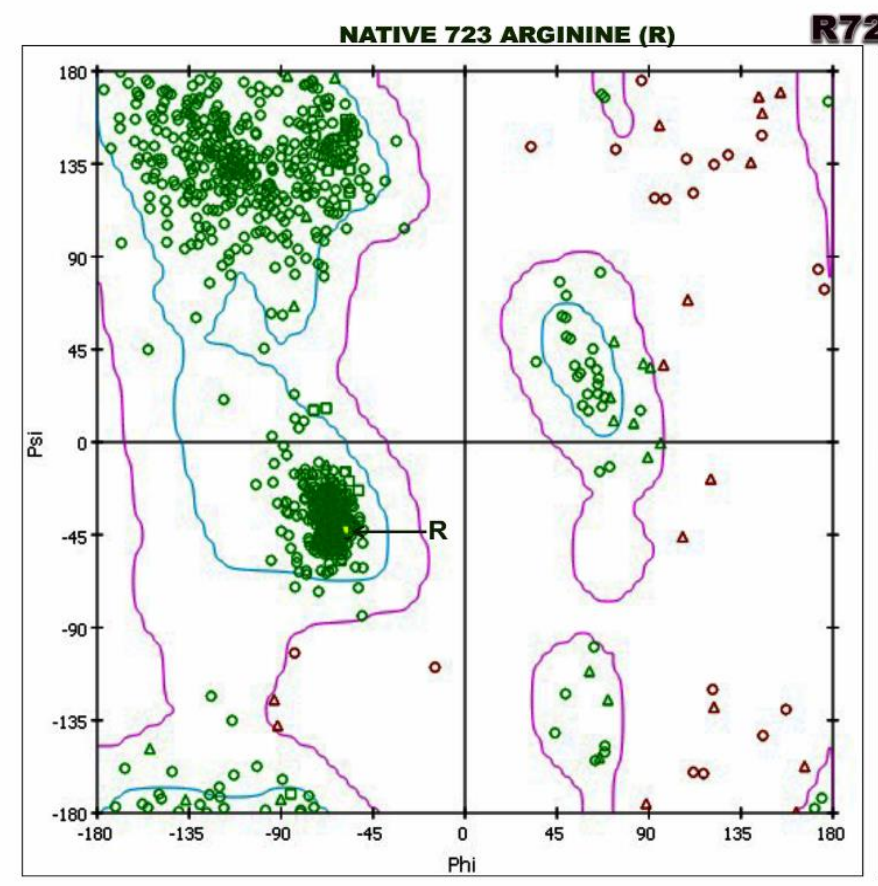

\section{-}

MUTANT 723 HISTIDINE (H)

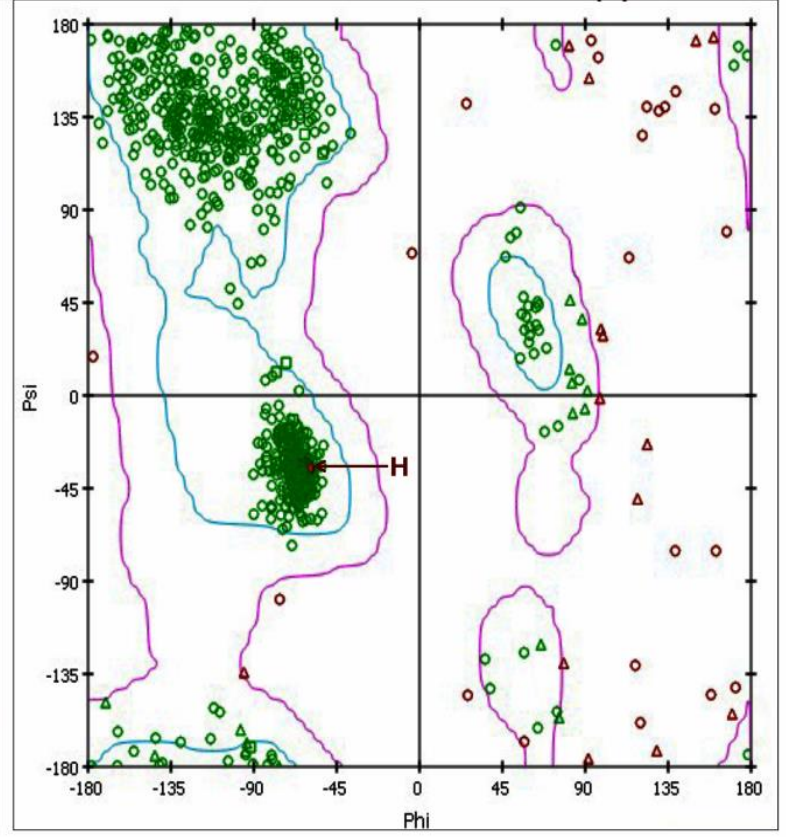

Figure 4: Ramachandran Plot, we compared the energetically allowed and disallowed regions of backbone dihedral angles $\psi$ against $\phi$ of amino acid residues in the homology model vs. native.

\section{Discussion}

Mutations in a gene can be benign or pathogenic, and it is often challenging to establish which variants are pathogenic. The $M Y H 7$ is reported to be an important gene, and its mutations may lead to both HCM as well as DCM pathogenesis. Therefore, it is difficult to understand how a mutation can contribute to disease onset and how a gene mutation causes diverse cardiomyopathy phenotypes. In the present study, we found a nsSNP (Arg723His) in the head motor domain of $\beta$-MYH7 in a HCM patient (Figure.1A). However, we previously reported the same missense mutation Arg723His along with two other variations [(IVS19-1G) G>A, Ala729Ala] in exon 20 of the $\beta-M Y H 7$ gene (allelic heterogeneity) in a DCM patient and her son [34] [Rani et al 2021]. Thus, strongly reinforcing phenotypic plasticity in the presence of the compound mutation besides environmental background, epigenetic modifications/other factors, etc., [35,36]. The role of epidemiological factors in the pathogenetic process gains even more prominence because a single mutation can sometimes give rise to two very divergent phenotypes, emphasizing the role of gene modifiers and the influence of environmental factors in accounting for phenotypic plasticity [37,38]. This missense mutation $\mathrm{R} 723 \mathrm{H}$ was absent in 207 healthy individuals. The mutant p.His 723 has been found to alter evolutionarily conserved amino acids. It was predicted pathogenic by Polyphen-2 and SIFT bioinformatic tools. Further, we found that the mutant p. His723 (homology model) uniquely disrupts and deviates a critical network of non-bonding interactions at the mutation site (Table2; Fig.2). We know that a network of different kinds of non-covalent interactions between the amino acid residues drive the accurate 3D structure of the protein. Though different kinds of molecular interactions determine the accurate $3 \mathrm{D}$ structure of the protein, a network of non-covalent interactions between them is crucial [39]. We showed hydrophobicity plot (Figure.3; Table S1) and the Ramachandran plot (Figure.4; Table S2) to understand the deviation in mutant protein structure. Though different sequences map to a similar structure, a nsSNP can dramatically change a protein structure and lead to disease phenotype, such as sickle cell anemia (glutamic acid to valine (E6V) in the $\beta$-globin) [40]. Some studies suggest that the abnormal proteins themselves serve as pathogenic agents and are associated with various diseases [41]. However, functional studies are needed to confirm the actual pathogenic effect of this mutation.

\section{Conclusion}

Here, we have demonstrated how the (p.His723) mutant disrupted a critical non-covalent interactions network that possibly affects the structure and function. Therefore, understanding the impact of nsSNP on protein structure is indispensable for targeting the mutant amino acid residue for therapeutic purposes. Our findings in future could pave the way for developing small molecular modulators or myosin-targeted therapies for failing hearts.

\section{Acknowledgments}

We acknowledge all the hypertrophic cardiomyopathy patients and healthy controls for willingly contributed their blood samples for analyses.

\section{Conflict of Interest}

The authors have declared that there is no conflict of interest exist.

\section{Funding Source}

D. S. Rani is salaried through CSIR_CCMB, Hyderabad, India. CSIR/CCMB funded this project. The funders had no role in study design, data collection and analysis, decision to publish, or preparation of the manuscript.

\section{Author Contributions}

D.S.R. and K.T. conceived and designed the experiments. D.S.R performed PCR, Direct sequencing and mutation screening. D.S.R has done RMSD and Non-bonding interaction Insilico analysis with technical help from A.S. Cases and control samples were received from G.V.S., and E.C. 


\section{References}

1 Yates CM, Sternberg MJ: The effects of non-synonymous single nucleotide polymorphisms (nsSNPs) on protein-protein interactions. J Mol Biol 2013;425:3949-3963.

2 Ajay SS, Parker SC, Abaan HO, Fajardo KV, Margulies EH: Accurate and comprehensive sequencing of personal genomes. Genome Res 2011;21:1498-1505.

3 Ramensky V, Bork P, Sunyaev S: Human non-synonymous SNPs: server and survey. Nucleic Acids Res 2002;30:38943900.

4 Bamshad MJ, Ng SB, Bigham AW, Tabor HK, Emond MJ, Nickerson DA, Shendure J: Exome sequencing as a tool for Mendelian disease gene discovery. Nat Rev Genet 2011;12:745-755.

5 Stenson PD, Mort M, Ball EV, Howells K, Phillips AD, Thomas NS, Cooper DN: The Human Gene Mutation Database: 2008 update. Genome Med 2009;1:13.

6 Anan R, Greve G, Thierfelder L, Watkins H, McKenna WJ, Solomon S, Vecchio C, Shono H, Nakao S, Tanaka H, et al.: Prognostic implications of novel beta cardiac myosin heavy chain gene mutations that cause familial hypertrophic cardiomyopathy. J Clin Invest 1994;93:280-285.

7 International HapMap C: A haplotype map of the human genome. Nature 2005;437:1299-1320.

8 Simpson S, Rutland P, Rutland CS: Genomic Insights into Cardiomyopathies: A Comparative Cross-Species Review. Vet Sci 2017;4

9 Rangaraju A, Rani DS, Satyanarayana M, Calambur N, Swapna N, Nallari P: Genetic variations of alpha-cardiac actin and cardiac muscle LIM protein in hypertrophic cardiomyopathy in South India. Exp Clin Cardiol 2012;17:26-29.

10 Rani DS, Nallari P, Narasimhan C, Thangaraj K (2019). Novel Variations in $\beta$ - Myosin Heavy-Chain Gene ( $\beta$-MYH7) and Its Association in South Indian Women with Cardiomyopathies. Indian Journal of Cardiovascular Disease in Women.2019; WINCARS 4 (02), 072-078.

11 Rani DS, Dhandapany PS, Nallari P, Narasimhan C, Thangaraj $\mathrm{K}$ : A novel arginine to tryptophan (R144W) mutation in troponin $\mathrm{T}(\mathrm{cTnT})$ gene in an indian multigenerational family with dilated cardiomyopathy (FDCM). PLoS One 2014;9:e101451.

12 Rani DS, Nallari P, Dhandapany PS, Tamilarasi S, Shah A, Archana V, AshokKumar M, Narasimhan C, Singh L, Thangaraj K: Cardiac Troponin T (TNNT2) mutations are less prevalent in Indian hypertrophic cardiomyopathy patients. DNA Cell Biol 2012;31:616-624.

13 Rani DS, Nallari P, Priyamvada S, Narasimhan C, Singh L, Thangaraj K: High prevalence of Arginine to Glutamine substitution at 98, 141 and 162 positions in Troponin I (TNNI3) associated with hypertrophic cardiomyopathy among Indians. BMC Med Genet 2012;13:69.

14 Seidman JG, Seidman C: The genetic basis for cardiomyopathy: from mutation identification to mechanistic paradigms. Cell 2001;104:557-567.

15 Selvi Rani D, Nallari P, Dhandapany PS, Rani J, Meraj K, Ganesan M, Narasimhan C, Thangaraj K: Coexistence of Digenic Mutations in Both Thin (TPM1) and Thick (MYH7) Filaments of Sarcomeric Genes Leads to Severe Hypertrophic Cardiomyopathy in a South Indian FHCM. DNA Cell Biol 2015;34:350-359.

16 McCartan C, Mason R, Jayasinghe SR, Griffiths LR: Cardiomyopathy classification: ongoing debate in the genomics era. Biochem Res Int 2012;2012:796926.
17 Maron BJ, Gardin JM, Flack JM, Gidding SS, Kurosaki TT, Bild DE: Prevalence of hypertrophic cardiomyopathy in a general population of young adults. Echocardiographic analysis of 4111 subjects in the CARDIA Study. Coronary Artery Risk Development in (Young) Adults. Circulation 1995;92:785-789.

18 Arai S, Matsuoka R, Hirayama K, Sakurai H, Tamura M, Ozawa T, Kimura M, Imamura S, Furutani Y, Joh-o K, et al.: Missense mutation of the beta-cardiac myosin heavy-chain gene in hypertrophic cardiomyopathy. Am J Med Genet 1995;58:267-276.

19 Lankford EB, Epstein ND, Fananapazir L, Sweeney HL: Abnormal contractile properties of muscle fibers expressing beta-myosin heavy chain gene mutations in patients with hypertrophic cardiomyopathy. J Clin Invest 1995;95:14091414.

20 Rayment I, Holden HM, Sellers JR, Fananapazir L, Epstein ND: Structural interpretation of the mutations in the beta-cardiac myosin that have been implicated in familial hypertrophic cardiomyopathy. Proc Natl Acad Sci U S A 1995;92:38643868.

21 Woo A, Rakowski H, Liew JC, Zhao MS, Liew CC, Parker TG, Zeller M, Wigle ED, Sole MJ: Mutations of the beta myosin heavy chain gene in hypertrophic cardiomyopathy: critical functional sites determine prognosis. Heart 2003;89:11791185.

22 Kelly DP, Strauss AW: Inherited cardiomyopathies. N Engl J Med 1994;330:913-919.

23 Das KJ, Ingles J, Bagnall RD, Semsarian C: Determining pathogenicity of genetic variants in hypertrophic cardiomyopathy: importance of periodic reassessment. Genet Med 2014;16:286-293.

24 Hougs L, Havndrup O, Bundgaard H, Kober L, Vuust J, Larsen LA, Christiansen M, Andersen PS: One third of Danish hypertrophic cardiomyopathy patients with $\mathrm{MYH7}$ mutations have mutations [corrected] in MYH7 rod region. Eur J Hum Genet 2005;13:161-165.

25 Matsushita Y, Furukawa T, Kasanuki H, Nishibatake M, Kurihara Y, Ikeda A, Kamatani N, Takeshima H, Matsuoka R: Mutation of junctophilin type 2 associated with hypertrophic cardiomyopathy. J Hum Genet 2007;52:543-548.

26 Arad M, Penas-Lado M, Monserrat L, Maron BJ, Sherrid M, Ho CY, Barr S, Karim A, Olson TM, Kamisago M, Seidman JG, Seidman CE: Gene mutations in apical hypertrophic cardiomyopathy. Circulation 2005;112:2805-2811.

27 Khurana JK, Reeder JE, Shrimpton AE, Thakar J: GESPA: classifying nsSNPs to predict disease association. BMC Bioinformatics 2015;16:228.

28 Stenson PD, Mort M, Ball EV, Chapman M, Evans K, Azevedo L, Hayden M, Heywood S, Millar DS, Phillips AD, Cooper DN: The Human Gene Mutation Database $(\operatorname{HGMD}((\mathrm{R})))$ : optimizing its use in a clinical diagnostic or research setting. Hum Genet 2020;139:1197-1207.

29 Keskin O, Tuncbag N, Gursoy A: Predicting Protein-Protein Interactions from the Molecular to the Proteome Level. Chem Rev 2016;116:4884-4909.

30 Adzhubei IA, Schmidt S, Peshkin L, Ramensky VE, Gerasimova A, Bork P, Kondrashov AS, Sunyaev SR: A method and server for predicting damaging missense mutations. Nat Methods 2010;7:248-249.

$31 \mathrm{Ng}$ PC, Henikoff S: SIFT: Predicting amino acid changes that affect protein function. Nucleic Acids Res 2003;31:3812-3814.

32 Biasini M, Bienert S, Waterhouse A, Arnold K, Studer G, Schmidt T, Kiefer F, Gallo Cassarino T, Bertoni M, Bordoli L, Schwede T: SWISS-MODEL: modelling protein tertiary and 
quaternary structure using evolutionary information. Nucleic Acids Res 2014;42:W252-258.

33 Winkelmann DA, Forgacs E, Miller MT, Stock AM: Structural basis for drug-induced allosteric changes to human beta-cardiac myosin motor activity. Nat Commun 2015;6:7974.

34 DS Rani, AV Kumar, P Nallari, K Sampathkumar, PS Dhandapany, A Rathinavel, C Narasimhan, K Thangaraj. "Novel mutations in $\beta$-MYH7 gene in Indian patients with dilated cardiomyopathy" CJC Open. 2021/8/8.

35 Geisterfer-Lowrance AA, Kass S, Tanigawa G, Vosberg HP, McKenna W, Seidman CE, Seidman JG: A molecular basis for familial hypertrophic cardiomyopathy: a beta cardiac myosin heavy chain gene missense mutation. Cell 1990;62:999-1006.

36 Marian AJ: Phenotypic plasticity of sarcomeric protein mutations. J Am Coll Cardiol 2007;49:2427-2429.

37 Fatkin D, Graham RM: Molecular mechanisms of inherited cardiomyopathies. Physiol Rev 2002;82:945-980.
38 Mogensen J, Murphy RT, Kubo T, Bahl A, Moon JC, Klausen IC, Elliott PM, McKenna WJ: Frequency and clinical expression of cardiac troponin I mutations in 748 consecutive families with hypertrophic cardiomyopathy. J Am Coll Cardiol 2004;44:2315-2325.

39 Lesser GJ, Rose GD: Hydrophobicity of amino acid subgroups in proteins. Proteins 1990;8:6-13.

40 Ingram VM: Gene mutations in human haemoglobin: the chemical difference between normal and sickle cell haemoglobin. Nature 1957;180:326-328.

41 Ma J, Yee A, Brewer HB, Jr., Das S, Potter H: Amyloidassociated proteins alpha 1-antichymotrypsin and apolipoprotein E promote assembly of Alzheimer beta-protein into filaments. Nature 1994;372:92-94.

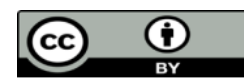

This work is licensed under Creative Commons Attribution 4.0 License

\section{To Submit Your Article Click Here:}

Submit Manuscript
Ready to submit your research? Choose Auctores and benefit from:

* fast, convenient online submission

* rigorous peer review by experienced research in your field

* rapid publication on acceptance

* authors retain copyrights

* unique DOI for all articles

* immediate, unrestricted online access

At Auctores, research is always in progress.

Learn more www.auctoresonline.org/journals/clinical-cardiology-andcardiovascular-interventions 